Christian Gostečnik, ORCID: https://orcid.org/0000-0001-5973-0145

Robert Cvetek, ORCID: https://orcid.org/0000-0002-3048-9965

Tanja Pate, ORCID: https://orcid.org/0000-0001-9570-5617

Saša Poljak Lukek, ORCID: https://orcid.org/0000-0001-9833-0339

Barbara Simonič, ORCID: https://orcid.org/0000-0002-5842-2017

Tanja Valenta, ORCID: https://orcid.org/0000-0003-3924-9607

Tanja Repič Slavič, ORCID: https://orcid.org/0000-0002-1524-453X

University of Ljubljana, Slovenia

\title{
The Impact of Early Aggression on Late Development*
}

\begin{abstract}
Children who are victims of an early violent atmosphere or early relational trauma will often, even in adulthood, tend to behave violently towards others, or become victims of violence, or freeze and later develop the tendency towards self-injury, in particular in later adolescence. In adulthood, they can be accident-prone, engage in constant violent physical abuse, threaten with or actually commit suicide. In this article we will focus on the impact of violence that children experience from the earliest age, on how it affects their development, and is transmitted to adulthood as well as to younger generations, since violence is imprinted in the deepest organic fibres of every individual.
\end{abstract}

* The authors acknowledge partial financial support from the Slovenian Research Agency (project No. J5-9349) 


\section{Keywords}

Affective dynamic, child and adolescent development, transmission of violence to adulthood, effects of violence in adulthood.

\section{Introduction}

Recent studies have shown that the perception of aggression of children who are exposed to extreme aggressive, violent emotions in families with alcohol abuse and, consequently, to brutality and aggression, can significantly change even at a later age. There are three types of responses ${ }^{1}$ : children in the first category are extraordinarily vulnerable and respond with extreme fear to every impulse, albeit quite innocent, that could present danger. For example, a mere sight of alcohol or someone who enjoys alcohol can awaken fear and horror. In the second category, there are children who do not perceive even real danger, and therefore behave as though nothing particular has happened. They have ceased to respond to brutality and cruelty, e.g. by their fathers, since their response has completely frozen long ago. The third category consists of children who become extremely aggressive, especially when they feel the atmosphere of aggression around them. They can be totally aggressive even when there is no real cause for aggression, but a certain sensation which has awakened within automatically leads to such response. ${ }^{2}$

\section{Affects of aggression}

It can be said that aggressive affects scar a growing child in a particular way. For example, when a child is harshly physically punished for his reactions and inadequate behaviour, extreme responses of anger, shame and humiliation can

${ }^{1}$ D. G. Dutton, The Abusive Personality: Violence and Control in Intimate Relationships, New York 2007, The Guilford Press, p. 75-79; J. R. Temple et al., Childhood Corporal Punishment and Future Perpetration of Physical Dating Violence, “The Journal of Pediatrics", 194 (2018), pp. 233-237.

${ }^{2}$ A. Schore, Affect regulation and the origin of the self: The neurobiology of emotional development, New York 2016, Taylor \& Frances/Routledge, p. 388-395; J. Henry, M. Sloane and C. Black-Pond, Neurobiology and neurodevelopmental impact of childhood traumatic stress and prenatal alcohol exposure, "Language, speech, and hearing services in schools", 38 (2007), pp.99-108. 
be awakened in the child. Sometimes he is even punished because he has frozen and parents see him as bad and impertinent because he refuses to speak, but his eyes reflect contempt and hatred. He can be punished because he is afraid, which can be reflected in screaming, crying, escaping from violence, hiding or even fleeing from home. In short, in all these cases, parental response is inappropriate: they (even physically, by beating) punish the child for his response which they perceive as inappropriate, because they understand that the child wants to shame and humiliate them with his responses and show them how very inadequate they are as parents. ${ }^{3}$

A particular type of aggression can also be exerted on children, when parents are involved in a fierce conflict, demanding from the child to take sides and accusing him that he either exaggerates about the aggressiveness of one of the parents, or does not cooperate sufficiently with the parent who suffers and is the victim of violence. This is particularly the case in families with alcohol abuse and other addictions, especially addiction to violence. It also occurs in families where the parents are going through the process of separation or are separated, and in doing so they cannot understand that it is they who are separating, and that children are absolutely innocent victims who are utterly powerless. These parents will often seek supportive listeners in their children and literally play the children off against each other. The children will experience more and more turmoil, distress, even sheer terror and utter confusion, as they will no longer know who to cooperate with. Anger and rage, deep sadness, disappointment and a feeling of shame will remain part of their daily experience, without any possibility of resolution, as these contents are literally inserted into their somatic fibres, i.e. their implicit memory. In these cases, both parents will require unconditional loyalty from children, which the children will often understand as having to simply renounce one of the parents, if they want to cooperate with the other, who will then take care of them. ${ }^{4}$

${ }^{3}$ J. R. Temple et al., Childhood Corporal Punishment and Future Perpetration of Physical Dating Violence, "The Journal of Pediatrics", 194 (2018), pp. 235-237.

${ }^{4}$ P. Frewen, R. Lanius, Healing the traumatized self: Consciousness, neuroscience, and treatment, New York 2015, W. W. Norton \& Company, p. 73-77. 


\subsection{Aggression and psycho-organic structure}

An increasing number of studies shows that, in addition to the fact that aggression by the parents is deeply rooted in the child's psycho-organic structure, the elements of aggression can also strongly manifest later in life and are even transmitted to next generations. For example, a child or a teenager who was beaten hard by his father can become an aggressive child or adolescent. This is a distinct paradox, since the very behaviour which the father supposedly stopped in this case, actually consolidates it in the child even more firmly. Here we must point out that the child is not necessarily aggressive towards his environment, but he always "does something", for which he is repeatedly aggressively treated by his peers. In this way he becomes the scapegoat, a target of their aggressive angry impulses, just as he was once the victim of father's or parental dysregulated aggressive affects. This child can also freeze or begin to avoid his mates, even when there is no obvious reason for doing so. He is more and more isolated, and feels increasingly lonely, since every stressful social environment can completely disable his functioning.

In these cases, the child's inner world, his psycho-organic system, remains full of dysregulated aggressive affects, which he cannot bear and can therefore easily fall ill or begin to develop genuine panic attacks and phobias. ${ }^{5}$ The development of this child's subcortical, as well as cortical brain development, is hindered, since he does not learn basic social adaptive functions, and therefore feels awkward in his social environment. What further increases his isolation is the fact that he often feels intense fear towards any authority or, on the other hand, despises the rules and especially those who set these rules. In this way, he continues to express his deeply embedded pain which is all permeated with aggressive affects; when he does not show active resistance, his extremely passive attitude is only an outward expression of covert resistance, which is deeply suppressed because of fear. Such a child can be very slow, constantly late, forgetful, and is always lost in his world of daydreaming and boredom. Because of this, he finds himself at the very margin of his peer group, who can be extremely cruel and often rude towards him, because his behaviour always triggers their mockery and contempt.

${ }^{5}$ K. Steele, S. Boon, O. van der Hart, Treating Trauma-Related Dissociation: A Practical, Integrative Approach, New York 2016, W. W. Norton \& Company, p. 7-13; J. B. Kaplow, C. S. Widom, Age of onset of child maltreatment predicts long-term mental health outcomes, "Journal of abnormal Psychology", 116 (2007), pp. 177-179. 
In addition, the aforementioned research ${ }^{6}$ proves that in the individual psycho-organic system, not only trauma is found, but also the response that was used in the fight-or-flight response to trauma. This further confirms why the models for dealing with trauma are so deeply embedded in the individual's psycho-organic system. An example of this are parents who used to be violence victims in their own families. Although they consciously make a decision and commit themselves not to physically punish or even abuse their child, in stressful situations caused by, for example, the child's inappropriate behaviour, they automatically respond in the way they were treated in their own childhood. They can harshly criticize, humiliate, shame, hit or even cruelly beat their child in other words, treat him in the same way they once suffered from their parents. These responses are usually a carbon copy of parental reactions to their inappropriate behaviours and often come as a surprise to them, since not in their wildest dreams had they thought that they could be so cruel, sometimes even brutal towards their own child.

An increasing number of neurobiological studies point to the fact that an adult can react to certain stressful situations - which are very serious from his point of view - with an extremely strong regression to the state of an infant. ${ }^{7}$ In other words, this individual, who has experienced relational trauma during childhood, may appear fully functional in adulthood, but when serious stress or trauma occurs, he is completely inhibited, and he acts incompatibly, incorrectly and inappropriately in relation to the situation or stimuli coming from the environment. The same as children in their early childhood and adolescence,

${ }^{6}$ A. Schore, Affect regulation and the origin of the self: The neurobiology of emotional development, New York 2016, Taylor \& Frances/Routledge, p. 445-457; B. Rothschild, The body remembers, Volume 2: Revolutionizing trauma treatment, New York 2017, W. W. Norton \& Company, p. 74-80; K. Steele, S. Boon, O. van der Hart, Treating Trauma-Related Dissociation: A Practical, Integrative Approach, New York 2016, W. W. Norton \& Company, p. 432-437; J. B. Kaplow, C. S. Widom, Age of onset of child maltreatment predicts long-term mental health outcomes, "Journal of abnormal Psychology", 116 (2007), pp. 177-179; K. L. Shipman et al., Maternal emotion socialization in maltreating and non-maltreating families: Implications for children's emotion regulation, "Social Development", 16 (2007), pp. 268-285.

7 A. Schore, Affect regulation and the origin of the self: The neurobiology of emotional development, New York 2016, Taylor \& Frances/Routledge, p. 485-489; B. Rothschild, The body remembers, Volume 2: Revolutionizing trauma treatment, New York 2017, W. W. Norton \& Company, p. 76-79; G. L. Schmelzer, Journey through trauma: A trail guide to the 5-phase cycle of healing repeated trauma, New York 2018, Avery Publishing Group, p. 63-72; J. B. Kaplow, C. S. Widom, Age of onset of child maltreatment predicts long-term mental health outcomes, “Journal of abnormal Psychology", 116 (2007), pp. 179-182. 
adults who have been traumatized during their childhood, react with extreme responses. For example, to an event that can be a completely innocent interpersonal conflict for others, he responds in an extremely traumatic manner, since the event is too stressful to bear for him. A similar reaction can be observed in children who are exposed to stressful situations in cases of physical and sexual abuse. In such situations, these children literally resort to the state of amnesia and dissociation, since this is the only way for them to have survived that early trauma.

\subsection{Dissociation and post-traumatic stress disorder}

As explained above, in addition to trauma, the defence mechanism is established in the child, and in this connection, we should first mention dissociations. These can have extremely catastrophic effects in this regard, as they damage the basic perceptions of the individual and in this connection his basic psychoorganic functions, too. An individual who suffers from dissociations, which can be largely a consequence of post-traumatic stress disorder, is often also the victim of a variety of misconceptions of both himself and others, which may be accompanied by a variety of somatic symptoms. ${ }^{8}$ Clinical research proves that there is a highly strong link between a traumatic experience in childhood and a somatoform dissociation of chronic PTSD in adulthood. ${ }^{9}$ In this case, dissociations are manifested primarily in autonomous physiological processes, such as heart rate and breathing, which can greatly change when the individual remembers the traumatic situation. ${ }^{10}$ In addition, studies prove that in children, and later in adults, who experience the effects of trauma, there are constant shifts between cognitive and affective-somatic aspects of dissociation, which means

8 J. N. Briere, C. Scott, Principles of Trauma Therapy: A Guide to Symptoms, Evaluation, and Treatment (DSM-5 Update), Los Angeles, CA, 2015, Sage Publications, p. 25-37; B. Rothschild, The body remembers, Volume 2: Revolutionizing trauma treatment, New York 2017, W. W. Norton \& Company, p. 17-23.

9 J. Kienle, B. Rockstroh, M. Bohus, J. Fiess, S. Huffziger, A. Steffen-Klatt, Somatoform dissociation and posttraumatic stress syndrome-two sides of the same medal? A comparison of symptom profiles, trauma history and altered affect regulation between patients with functional neurological symptoms and patients with PTSD, "BMC psychiatry", 17 (2017), pp. 220-231.

${ }^{10} \mathrm{~B}$. van der Kolk, The body keeps the score: Mind, brain and body in the transformation of trauma, New York 2014, Penguin Books, p. 51-74; K. Steele, S. Boon, O. van der Hart, Treating Trauma-Related Dissociation: A Practical, Integrative Approach, New York 2016, W. W. Norton \& Company, p. 262-267. 
that in such cases, these are dissociations between the emotional assessment of the event and the physiological reaction to this event, a process that essentially depends on the functioning of the right hemisphere.

Post-traumatic stress disorder in childhood shows serious dysfunction in the developing right hemisphere, the tasks of which are to develop attachment, regulatory functions, strategies for coping with stress, and to develop and maintain a coherent sense of self. These disorders, however, do not appear only in the right hemisphere, but can later become part of the entire brain activity, since each previous developmental stage predicts the possibility of growth in the next developmental stage. ${ }^{11}$ In other words, this means that relational traumas can extraordinarily impact further development, particularly in the individual's ability to adapt to the environment, as well as in the ability to recognize and distinguish what comes from the outside, i.e. from the environment, and what originates in the individual's inner world.

\subsection{Relational trauma}

Relational trauma can cause structural changes in the right hemispheric functions, in particular the right part of the limbic system, which is responsible for the processing of stress. Therefore for a child who was traumatized at the earliest age and has been exposed to new traumas later in life, even the most insignificant stress in interpersonal relationships can be interpreted by this individual as something extremely important and sometimes even disastrous. This is particularly true in relationships, where fears and horrors are constantly lurking; they are in fact related to past events, but the individual cannot perceive them as such, since they have such an extraordinary power in his present life that they are completely overwhelming. We are definitely talking about the consequences of PTSD from the earliest age, when the individual does not even know what has happened to him and cannot understand where these sensations and fear come from. ${ }^{12}$ One could argue that this is the most unjust heritage that the child carries, especially in the case of traumas that are the result of generational

${ }^{11}$ B. van der Kolk, The body keeps the score: Mind, brain and body in the transformation of trauma, New York 2014, Penguin Books, p. 87-95; A. Schore, Affect regulation and the origin of the self: The neurobiology of emotional development, New York 2016, Taylor \& Frances/ Routledge, p. 287-297.

12 B. van der Kolk, The body keeps the score: Mind, brain and body in the transformation of trauma, New York 2014, Penguin Books, p. 174-282; B. Rothschild, The body remembers, 
transmissions and the individual who becomes the carrier of these traumas did not even experience them, but they are embedded in his organic fibres and can evoke sensations that are entirely part of, for example, his mother or father.

\section{Early experiences of aggressive affects and adulthood}

Even before birth, but especially from birth, the child's body keenly perceives the tension and distress in its environment, but it is aggression that it perceives much more deeply. The earlier the experience of violence, the more deeply it is embedded in its evolving psycho-organic structure. ${ }^{13} \mathrm{~A}$ child who merely feels this aggression, or actually sees or observes it in his surroundings, becomes an immediate victim of this aggression and/or later actively transmits it to others. Today, we witness the violence that is taking place all over the world, communicated through television screens, films that are full of violent, murderous scenes, etc. The fact that probably raises the most concern is that films for children and youngsters are increasingly overwhelmed with violence, brutality and horrific scenes of killing that young viewers watch and literally absorb. There is no doubt that television can significantly affect children's reactions when they encounter violence, but it is necessary to take into account other factors that, as a result of violence, affect the whole brain structure and its development. Children who tend to respond aggressively can certainly be genetically predisposed to violence, but we can say that children who repeatedly witness violence on television screens are more prone to violent responses when confronted with conflicts, than those who are not exposed to violent films.

Quite clearly, however, research shows that children who are the victims of violence in their homes (both those who are witnesses and those who are direct victims of physical and particularly sexual abuse) are later inclined toward violence in their intimate relationships. ${ }^{14}$ In this regard, research even

Volume 2: Revolutionizing trauma treatment, New York 2017, W. W. Norton \& Company, p. 85-93.

${ }_{13}$ B. Rothschild, The body remembers, Volume 2: Revolutionizing trauma treatment, New York 2017, W. W. Norton \& Company, p. 133-147; K. F. Dyer et al, Comparing shame in clinical and nonclinical populations: Preliminary findings, "Psychological Trauma: Theory, Research, Practice, and Policy" 9 (2017), pp. 173-180.

${ }_{14}$ B. Rothschild, The body remembers, Volume 2: Revolutionizing trauma treatment, New York 2017, W. W. Norton \& Company, p. 74-77; K. L. Shipman et al., Maternal emotion 
demonstrates that children who are witnesses of physical abuse between their parents are three times more inclined to abuse their partner or to become victims of partner violence than those children who have not been exposed to violence between their parents. Unlike the first group, the second group has developed suitable models for coping with stressful situations. ${ }^{15}$ Here, it is necessary to mention an important fact that even those children who, having experienced violence with their parents, literally froze, can subconsciously transmit aggressive affects, which are suppressed in their psycho-organic structure, to their descendants, who often experience fear, horror, panic attacks and phobias, not even knowing where they originate, only feeling the sensations which are so powerful that they feel utterly helpless.

In particular, children are extremely sensitive and susceptible in this respect because, due to their evolving brain structure, they are incapable of resisting violence, which therefore literally flows directly into their brain centres. At the same time, violence becomes the basic organizer and even the regulator of all essential feelings and affects, since all are stained with the affects of anger, fear and terror, the fundamental elements of any violence. In other words, aggression so thoroughly permeates the psycho-organic system of every individual that, from now on, it becomes the main organizer of experience, perception and even meaning. The members of the family that is sprinkled with aggressive affects, can thus react to the most innocent behaviour by further aggression or call it on themselves, which is especially typical of children. In addition, aggression becomes the main regulator of the tension and distress that the family faces. ${ }^{16}$ Family members begin to deal with their frustrations by means of aggression, so that they literally lash out at each other, thus continuing to project aggression against one another.

These dynamics do not end here. Children learn very quickly that the best way to quite organically calm their parents is to provoke them for so long that the parents eventually react with aggression. By doing this, they disburden the

socialization in maltreating and non-maltreating families: Implications for children's emotion regulation, "Social Development" 16 (2007), pp. 269-273.

15 D. G. Dutton, The Abusive Personality: Violence and Control in Intimate Relationships, New York 2007, The Guilford Press, p. 74-83; J. R. Temple et al., Childhood Corporal Punishment and Future Perpetration of Physical Dating Violence, “The Journal of Pediatrics” 194 (2018), pp. 234-235.

16 Temple et al., Childhood Corporal Punishment and Future Perpetration of Physical Dating Violence, “The Journal of Pediatrics”, 194 (2018), pp. 234-237. 
parents of their frustrations and organically calm them. Thus children become essential regulators of parental dysregulated aggressive affects. These children can be deeply traumatized, since the terror from those who should protect them is always extremely painful for them. And when parents behave cruelly and violently, children very soon learn that they cannot control this person, i.e. father or mother, and even less can they control or direct them in their angry outbursts, which are sometimes filled with rage, shame and disgust. They cannot even confront their parents with their unconscientious behaviours, and their only option is to hide in their room, behind a curtain, cover over their heads, or put on headphones and listen to music, and thus try to protect themselves. However, in doing this, they cannot really succeed because they depend on their family to which they belong. ${ }^{17}$

In adolescence, these responses can be followed by others, such as eating disorders, by which the youngster tries to communicate that she is no longer able to accept these unacceptable, cruel and, above all, crude affects. Anorexic disorder means that the adolescent is forced to accept these aggressive affects but cannot process them; she can also throw them up, which, in her psycho-organic world translates into bulimic disorder; or she is so utterly neglected and deprived that he subsequently begins to overeat, thereby trying to silence her profoundly wounded inner being. The adolescent can also use other mechanisms or defence attempts, which usually turn into running away from home, engaging in various cult groups, violent clans, gangster groups, etc. ${ }^{18}$ For the adolescent, all these escapes are one big attempt to get rid of aggressive attacks or at least to avoid them. In doing so, he always subconsciously hopes that the parents will hear him, that through his behaviour they will recognize his immense distress, how full of terror and terrible anxiety he is as a result of their aggressive behaviour. In short, this is the adolescent's extremely loud screaming for help. ${ }^{19}$

17 C. Greene et al., Psychological and physical intimate partner violence and young children's mental health: The role of maternal posttraumatic stress symptoms and parenting behaviors. "Child abuse \& neglect" 77 (2018), pp. 169-175.

18 P. Frewen, R. Lanius, Healing the traumatized self: Consciousness, neuroscience, and treatment, New York 2015, W. W. Norton \& Company, p. 23-31.

19 G. L. Schmelzer, Journey through trauma: A trail guide to the 5-phase cycle of healing repeated trauma, New York 2018, Avery Publishing Group, p. 123-157. 


\section{Psycho-organic changes}

These traumas always cause psycho-organic changes. Firstly, there is hyperarousal, which can manifest in perspiration, increased heart rate and shallow breathing; these symptoms are always the result of anxiety and anger, which is usually suppressed. This is why it is so exceptionally crucial to re-discover anger, which is an emotional response to a provocation ${ }^{20}$ and helps overcome less acceptable feelings, such as fear and guilt. This is especially important in an intimate couple relationship, where stressful interpersonal relations can give rise to anxiety, sometimes even sheer terror, causing, for example, one of the partners to perceive that he no longer has adequate control and, consequently, anxiety only increases. The partner feels that he is powerless, sometimes literally tied and without any chance of being able to react appropriately. That is why anger is so important, because the affect of anger is essentially an organic response to the injustice that is happening to him, and therefore it can help an individual to come in contact with himself again in order to regain his self-awareness and, consequently, own his dissociated elements or contents that have been suppressed. ${ }^{21}$

\subsection{The affect of anger}

Anger is the affect that is not necessarily awakened only in stressful situations. Of course this does not mean that we must express anger when, for example, we perceive that we are the target of injustice, that someone offended us, hurt us, forced us into a stressful situation; anger is, however, the basic initiator which helps us to become more active, to deal with stress with more energy, and confront provocation and injustice. This, of course, applies not only to stressful situations that come from outside, but also, and above all, to the stresses that we experience in intimate couple relationships. In any case, we should pay particular attention to regulating the affect of anger first, since dysregulated anger

20 D. G. Dutton, The Abusive Personality: Violence and Control in Intimate Relationships, New York 2007, The Guilford Press, p. 148-159; G. L. Schmelzer, Journey through trauma: A trail guide to the 5-phase cycle of healing repeated trauma, New York 2018, Avery Publishing Group, p. 160-169.

${ }^{21}$ P. Frewen, R. Lanius, Healing the traumatized self: Consciousness, neuroscience, and treatment, New York 2015, W. W. Norton \& Company, p. 35-43. 
can always be destructive, both to the person who feels it and to the other. ${ }^{22}$ Dysregulated anger remains part of the system, part of our environment. We unconsciously spread fear or terror, both derivatives of dysregulated, suppressed or dissociated anger, and therefore always become a dysregulated element that only expands in our organic-psychic world, and later, this atmosphere can spread everywhere we go.

In these cases, however, the affect of anger is an organic signal that the problem is still present and requires regulation or resolution, instead of using others as scapegoats, because we feel unsettled, torn and dissatisfied, which generates anger over and over again. However, anger is not just a signal that anxiety - and along with it a problem - has occurred, but also allows the individual to promote himself, giving him power, determination and the ability to express himself. These qualities allow an individual to be able to go forward steadily, to think more clearly and to become more confident. ${ }^{23}$ On this basis we can conclude that it is much more functional and less stressful for anyone to be angry than overwhelmed with anxiety. In other words, whenever an individual supresses anger, he becomes anxious, and whenever this individual is able to overcome anxiety, he becomes angry. ${ }^{24}$ If the affect of anger is not regulated in advance, however, it remains in its dysregulated form and is continually projected outside, the problem therefore remaining unresolved.

An outburst of anger, for example, can always lead to a greater or lesser form of aggression that is more or less socially acceptable. As a stereotype, men are inclined to dissociate fear and whenever anger arises in them, it can, in its dysregulated form, cause violence, either verbal or even physical. This may involve a variety of forms of expressing the affect of anger, ranging from cynical, sarcastic, cruel, humiliating and shameful expressions to physical attacks such as pushing a person or pulling hair, as well as heavy physical abuse. In all these

${ }^{22}$ D. G. Dutton, The Abusive Personality: Violence and Control in Intimate Relationships, New York 2007, The Guilford Press, p. 95-102; A. Schore, Affect regulation and the origin of the self: The neurobiology of emotional development, New York 2016, Taylor \& Frances/Routledge, p. 482-487; P. Ogden, J. Fisher, Sensorimotor psychotherapy: Interventions for trauma and attachment, New York 2015, W. W. Norton \& Company, p. 391-397.

${ }^{23}$ G. L. Schmelzer, Journey through trauma: A trail guide to the 5-phase cycle of healing repeated trauma, New York 2018, Avery Publishing Group, p. 227-235.

${ }^{24}$ D. G. Dutton, The Abusive Personality: Violence and Control in Intimate Relationships, New York 2007, The Guilford Press, p. 127-139; K. Steele, S. Boon, O. van der Hart, Treating Trauma-Related Dissociation: A Practical, Integrative Approach, New York 2016, W. W. Norton \& Company, p. 203-217. 
forms and expressions of anger, its fundamental dynamics is about how to get rid of the anger affect, i.e. to solve the conflict that has arisen. And most often, the innocent victims of these outbursts of anger are children as violent parents stick to the old rule that physical punishment is acceptable when it comes to cases of 'disobedient' children. According to these parents, such children need severe punishment for their behaviour. This punishment can also be accompanied by harsh words of despise and shame, full of cynicism, sarcasm, and severe humiliation. This kind of child-rearing is extremely inappropriate, since it never achieves the goal that these parents defend, but just the contrary.

\subsection{A subconscious attempt at resolving violence}

How deeply this abuse can be embedded in a child's implicit memory is shown by the fact that these children in adult intimate couple relationships where violence prevails also try to justify their aggression by saying that they were so rudely provoked that they simply could not help themselves because their partner literally forced them to behave aggressively. ${ }^{25}$ Even in these cases, when the partner's reactions are totally unbearable and incorrect, the one who uses violence and responds aggressively is always responsible for his actions. Here we refer to criminal acts, which are sometimes so infamous that they fill the first pages of daily newspapers, such as grave injury or even murder. These criminal acts go on and on, as the dynamics of the dysregulated affects of anger can be completely unpredictable and, as we shall see, they urgently need to be stopped before they escalate into these unpredictable hostile dimensions. ${ }^{26}$ All these violent outbursts are purely dysregulated and uncontrolled responses, which can by no means be acceptable, let alone justifiable.

All these forms of brutal, violent response are an unconscious organic attempt to regulate one's internal tension, permeated with anger and often with sheer terror, on the body level. ${ }^{27}$ Sometimes both partners use aggressive, violent

${ }^{25}$ D. G. Dutton, The Abusive Personality: Violence and Control in Intimate Relationships, New York 2007, The Guilford Press, p. 75-79; J. N. Briere, C. Scott, Principles of Trauma Therapy: A Guide to Symptoms, Evaluation, and Treatment (DSM-5 Update), Los Angeles, CA, 2015, Sage Publications, p. 127-139.

${ }^{26}$ D. G. Dutton, The Abusive Personality: Violence and Control in Intimate Relationships, New York 2007, The Guilford Press, p. 83-91.

${ }^{27}$ D. G. Dutton, The Abusive Personality: Violence and Control in Intimate Relationships, New York 2007, The Guilford Press, p. 75-79; K. Steele, S. Boon, O. van der Hart, Treating 
physical behaviours to calm down or regulate non-transferable aggressive affects. Furthermore, they are at least temporarily able to calm down after abuse. In addition, their behaviour is, paradoxically, often the way in which, after tense non-transferable affects, which they cannot carry any more, they reconcile, calm down and can again experience a more functional relationship, although only temporarily. This also involves rude sexual intercourse (quite similar to rape and sexual abuse), which can temporarily have an illusory calming effect, but has catastrophic consequences for both partners, since the body always remembers these brutal attacks.

Both partners, the sender of aversive affects and especially the receiver of these contents, will therefore be in an extremely difficult situation. Through highly negative and destructive attempts, they will strive to find the source of their pains - the scapegoat - in one another. They will become angry, and this anger allows them to externalize their distress and pain, as well as destructive elements that they can no longer carry. In other words, by finding the culprit for their internal anxiety state in the other, and, consequently, projecting their disruptive feelings on them, they get rid of these psychosomatic contents, instilling them in their partner. The partner can thus experience highly destructive sensations, which can cause freezing or, on the other hand, savage, violent outbursts of anger and rage towards the other. But this partner can become extremely self-destructive: by means of a variety of addictive substances, such as alcohol, and practices, such as sexuality and in this connection sexual abuse; by self-injury, injury to the other, suicide threats and attempts, which are often the way how partners blackmail each other, and through violence literally force each other into incredibly cruel acts. Partners can be quite different in their response to aggression. In this regard, a study was made on the basis of a TAT test ${ }^{28}$ with ambiguous images. The researcher seeks to evaluate participants' responses, stimulated on the basis of unconscious issues in their intrapsychic or psychoorganic structure. Because of the ambiguity of these images, each partner can project their own psycho-organic themes when describing them. These studies

Trauma-Related Dissociation: A Practical, Integrative Approach, New York 2016, W. W. Norton \& Company, p. 97-112; G. L. Schmelzer, Journey through trauma: A trail guide to the 5-phase cycle of healing repeated trauma, New York 2018, Avery Publishing Group, p. 123-133.

${ }^{28}$ D. G. Dutton, The Abusive Personality: Violence and Control in Intimate Relationships, New York 2007, The Guilford Press, p. 149-153; K. Steele, S. Boon, O. van der Hart, Treating Trauma-Related Dissociation: A Practical, Integrative Approach, New York 2016, W. W. Norton \& Company, p. 53-67. 
find that the partner in his responses conveys aggressive and violent themes, feeling danger or threat in these images. In doing so, women differ considerably from men; women describe images that are related to work situations or events that affect relationships at work with a higher degree of aggression, while men reflect much more aggression in connection with man-woman relationships. These findings are quite surprising, since we would expect men to pay more attention to work relationships and women to intimate partner relationships, and yet, according to research, it is far from being so.

According to this, researchers ${ }^{29}$ conclude that women do react highly aggressively to the frustrations that are associated with their intimate couple relationships, but their angry responses are much more intense when it comes to success and, in this regard, satisfaction at work, where they want to realize their full potential, prove themselves and succeed. Men, on the other hand, are much more sensitive when it comes to man-woman relationships, especially those that are intimate. According to these results, researchers ${ }^{30}$ conclude that women are not as much afraid of intimate relationships as men, but they become furious, showing highly aggressive responses, when their partner does not know how or does not want to listen when, for example, they try to confide in him, with great grief, disappointment and helplessness, what frustration they experience at work, how their superiors do not understand or appreciate them, how they humiliate or even embarrass them. They expect their partners to support and understand them and, above all, show empathy: and when they do not get it, they feel rejected, they feel that their partners do not take their problems seriously, and do not feel or appreciate their efforts. Because of this, they feel bitter contempt, deep sadness and sometimes even despair.

Men, on the other hand, are much more afraid of intimacy, and this fear can expand into extreme forms of aggression, since they cannot manage and control relationships. Therefore, they become angry and sometimes enraged to completely unpredictable levels, and consequently they inflict their angry

29 D. G. Dutton, The Abusive Personality: Violence and Control in Intimate Relationships, New York 2007, The Guilford Press, p. 149-153; J. N. Briere, C. Scott, Principles of Trauma Therapy: A Guide to Symptoms, Evaluation, and Treatment ( DSM-5 Update), Los Angeles, CA, 2015, Sage Publications, p. 27-29.

${ }^{30}$ D. G. Dutton, The Abusive Personality: Violence and Control in Intimate Relationships, New York 2007, The Guilford Press, p. 217-219; K. Steele, S. Boon, O. van der Hart, Treating Trauma-Related Dissociation: A Practical, Integrative Approach, New York 2016, W. W. Norton \& Company, p. 331-335. 
content on their partner who becomes the victim of their uncontrolled aggression. ${ }^{31}$ They often unconsciously transfer frustrations from their workplace, which they rarely talk about, directly to their intimate partner, to the wife who does not even know what is really happening, she only feels, and increasingly more so, that her husband does not appreciate, respect, or love her: rather, he utterly rejects her. She does not know, however, that her husband's job can often be a direct source of his problems, but he cannot express these problems in an acceptable form. Another thing she does not know is that her husband is extremely afraid to be vulnerable and therefore cannot communicate his frustration because he fears her criticism, her judgements and, above all, her lack of understanding. He therefore wants to completely remove his job from their conversations, although the problem is not his job but his extreme vulnerability, i.e. fear of closeness and intimacy, because in reality he is more afraid of intimacy than of his wife's feedback about his job. In any case, the job can always become part of the conflict, on the basis of which he resolves his fear of intimacy, since his wife's lack of understanding can always be a justifiable reason for him to withdraw.

\subsection{Aggression and the fear of intimacy}

Related research ${ }^{32}$ shows that these individuals are frightfully afraid that the partner will replace them in the next moment, i.e. as soon as they meet someone more attractive, and thus discard them, robbing them of everything, impoverishing them internally and leave them empty, and so much so that they will not be able to survive. We should first of all emphasize that the individual with violent, abusive personality characteristics is already looking for a partner with similar implicit, organic memories, and in this relationship, which can

${ }^{31}$ D. G. Dutton, The Abusive Personality: Violence and Control in Intimate Relationships, New York 2007, The Guilford Press, p. 211-213; K. Steele, S. Boon, O. van der Hart, Treating Trauma-Related Dissociation: A Practical, Integrative Approach, New York 2016, W. W. Norton \& Company, p. 142-147.

32 D. G. Dutton, The Abusive Personality: Violence and Control in Intimate Relationships, New York 2007, The Guilford Press, p. 223-225; P. Ogden, J. Fisher, Sensorimotor psychotherapy: Interventions for trauma and attachment, New York 2015, W. W. Norton \& Company, p. 97-102; A. Schore, Affect regulation and the origin of the self: The neurobiology of emotional development, New York 2016, Taylor \& Frances/Routledge, p. 243-345; P. Frewen, R. Lanius, Healing the traumatized self: Consciousness, neuroscience, and treatment, New York 2015, W. W. Norton \& Company, p. 73-77. 
be extremely brutal, they only awaken these memories in each other. Both are terribly afraid of closeness and so these angry, envious and jealous behavioural patterns allow them to stay at a safe distance, because they fear that the other will merely rob and discard them if they allow them to get too close. They feel that this fear and pain they will not be able to process, let alone live with. It is therefore a purely unconscious process, which is completely beyond their control, as in this relationship, memories of violence and trauma, in particular relational, are being unconsciously awakened; and these memories have in many cases become part of the partners' psycho-organic state, which repeatedly cry for external expression.

On a conscious level, these two partners often feel that they are meant to be together, that they belong to one another, because these feelings originate in their passionate organic responses; and at the same time they are so afraid of losing each other that they feel sheer terror. But it is impossible for them to admit how tightly they are tied together, and not because of love that encourages growth and autonomy, but often genuinely pathological dependence on the relationship in which they feel that the other must fully understand that they are their partner's property and that they must not have their own feelings and thoughts, because it is too threatening to them. They deeply dissociate this internal threat and project these threatening elements, as already said, to one another, and as a result of the partner's jealousy and envy, they feel increasingly threatened, restricted, constrained and terrorized. The partner who bears these frightening, violent jealous outbursts, feels that any contact with another person, even a most inconsequential one, can be extremely endangering, as it is already heralds potential breakup, meaning the terror of being discarded. Both partners therefore suffer immensely and resort to the most inappropriate responses, because they constantly feel that the other partner is on the brink of running away.

For these two, family outings, holidays and socializing with others are particularly frightening. They essentially do not trust themselves, which they handily hide and blame the other for potential leaving, which is the deepest expression of their covert self-distrust. In other words, a jealous and envious partner is constantly challenged to react inappropriately to emotional and organic insinuations from the environment: for example, he will always feel "seduced" by other women whom he will feel attracted to, and because he does not trust himself to act responsibly and decently, he will project these feelings, i.e. fears, to his partner; consequently, he will behave extremely brutally towards her. The abusive partner experiences a much higher degree of anxiety; the slightest partner's 
emotional impulse can feel as a threat, so he reacts with a much higher degree of anger and fury than other men would have reacted with in similar situations. That is why such an intimate relationship, which is permeated with horror and fear from being abandoned, will be deeply marked by ongoing conflicts. At any moment, these can escalate into a violent outbreak, which paradoxically sets them apart for at least some time and thus calms them down; but in the next moment, passionate organic longing can arise and, consequently, the partners reunite again.

\subsection{Regulation of aggressive affects}

The background of these outbreaks is marked by violence; two partners come from families where violence prevailed, and now, in sometimes terrifyingly similar situations, they react in an old manner they have learnt in their primary families. As said above, opportunities can be family trips, holidays, dancing, parties, or a smothering and stifling domestic atmosphere, full of tension resembling that one in the childhood home, and the partners simply find themselves in violent interactions. ${ }^{33}$ Therefore, a relational therapist will have to approach the two partners, who are literally drenched in violence, with extreme sensitivity, and compassionately, but with determination, guide them towards new ways of reacting. In other words, the partners will not only expect from the therapist to be able to calm them down, but above all, to be able to regulate their highly intimidating, dysregulated affects. This regulation means, as already said, that the therapist first tries to decisively stop any aggressive response, which is only the beginning of the therapeutic process. The mere abstinence from violence does not mean that violence is stopped or that it is regulated. Therefore, the victims of violence must also be prepared for very concrete strategies, which should not be abandoned, since any tolerance of violence can always have disastrous consequences.

This is especially important because emotionally intimate partners always unconsciously expect that the other will regulate their dysregulated difficult and often completely non-transferable feelings and affects, in short, psycho-organic

${ }_{33}$ D. G. Dutton, The Abusive Personality: Violence and Control in Intimate Relationships, New York 2007, The Guilford Press, p. 97-103; P. Frewen, R. Lanius, Healing the traumatized self: Consciousness, neuroscience, and treatment, New York 2015, W. W. Norton \& Company, p. 193-197; J. N. Briere, C. Scott, Principles of Trauma Therapy: A Guide to Symptoms, Evaluation, and Treatment ( DSM-5 Update), Los Angeles, CA, 2015, Sage Publications, p. 167-172. 
states, ${ }^{34}$ which are deeply embedded in their organic structure. For example, when the wife calls the police, or when she leaves the room for a while, or she goes away from the husband, she tries to set boundaries and thus protect him from his violent outbursts; at the same time, she, at least, initially regulates his aggressive affects. In this way she protects the husband and this is often the only way to prevent the worst, such as the possibility that he will become so aggressive that a real disaster will occur; she prevents him from becoming sexually violent and abusive, and protects their children, who are frequently victims of these traumas and violence. In particular, this is of utmost importance when the violent partner has psychopathologic traits, since such person has no compassion for his victim, either before his violent outburst, or after the disaster has already happened. This partner cannot feel compassion for the victim, or regret over what he committed. Because of that, he will totally deny his brutal deed, ignore it, minimize it, or at least intensely blame the victim for the violence he committed, namely that the victim provoked him, deserved his rude intervention and even "asked" for it, as this was the only way to calm her down.

With partners who are aware of their actions, and at least retrospectively, experience shame over and guilt of what they committed, and can take full responsibility for it, the therapist must expressly insist that they do not minimize their responsibility later, as this is always the direct way towards the returning of the aggressive behaviour. In doing so, the relational therapist must pay attention to phrases such as, "She provoked me; how many times I have told her that she shouldn't irritate me and challenge me; she, too, must accept her responsibility for these acts; I was under the influence of alcohol; many husbands are much worse than me; it was just an accident, because I did not mean it to turn out so bad..."35 In cases where the partner does not accept his full responsibility, the probability that he will again resort to violence is extremely high; he has

${ }^{34}$ A. Schore, Affect regulation and the origin of the self: The neurobiology of emotional development, New York 2016, Taylor \& Frances/Routledge, p. 415-417; K. Steele, S. Boon, O. van der Hart, Treating Trauma-Related Dissociation: A Practical, Integrative Approach, New York 2016, W. W. Norton \& Company, p. 345-347.

35 D. G. Dutton, The Abusive Personality: Violence and Control in Intimate Relationships, New York 2007, The Guilford Press, p. 125-129; J. N. Briere, C. Scott, Principles of Trauma Therapy: A Guide to Symptoms, Evaluation, and Treatment (DSM-5 Update), Los Angeles, CA, 2015, Sage Publications, p. 232-236; P. Frewen, R. Lanius, Healing the traumatized self: Consciousness, neuroscience, and treatment, New York 2015, W. W. Norton \& Company, p. 257-259; J. R. Temple et al., Childhood Corporal Punishment and Future Perpetration of Physical Dating Violence, "The Journal of Pediatrics" 194 (2018), pp. 236-237. 
not yet accepted the fact that violence is such a powerful part of him that he is not even aware of it, and is therefore even less able to regulate it. As long as he does not feel that this is essentially and completely his problem, it is impossible to expect that anything will change significantly. In these cases, we speak of a genuine addiction to violence.

That being said, the relational therapist should pay close attention to the wife's responses to her husband's violence. Almost as a rule, wives tend to very quickly "forget" the abuse and all the cruel affects it has awakened. As soon as the partner is again friendly, courteous, remorseful, compassionate and full of promises, he can convince them to return to him. Here we are talking about genuine frozenness, pure dissociation and the suppression of all rough affects that have been awakened in past conflicts; and although wives or partners often know - cognitively, sometimes also emotionally - that the old story will be repeated, they simply cannot resist this friendly invitation and sometimes they literally have no idea how they suddenly found themselves in the partner's embrace. ${ }^{36}$ It is a genuine trance, a purely unconscious force that allures these women on organic level, so that they again begin a relationship that is doomed to failure. Deeply embedded implicit memories evoke passionate organic attraction and these partners cannot resist, or at least they feel they cannot. The tragedy of this attraction, however, is that it contains violence, which these partners more or less deny, hoping that this time the relationship will be different. ${ }^{37}$

\subsection{Irrational beliefs}

These organic-chemical dynamics are accompanied by irrational beliefs that, at least as it is seen from the outside, extremely forcefully lead and direct both the violent partner and his victim. However, here we are not just talking about violence between partners, but also about violence against children, who are certainly even more tragic victims; as well as against the entire family system, since violence that pervades the family and all family members, is their most basic organizer. Irrational beliefs and, sometimes, genuine myths, only help these

${ }^{36}$ D. G. Dutton, The Abusive Personality: Violence and Control in Intimate Relationships, New York 2007, The Guilford Press, p. 77-81; C. Policastro, M. A. Finn. Coercive control and physical violence in older adults: Analysis using data from the National Elder Mistreatment Study, "Journal of interpersonal violence" 32 (2017), pp. 313-317.

37 D. G. Dutton, The Abusive Personality: Violence and Control in Intimate Relationships, New York 2007, The Guilford Press, p. 119-121. 
ideas to expand, to be maintained and preserved. Obviously, these irrational beliefs are merely "the tip of the iceberg," just a cover, on the basis of which the violent partners try to apologize for their aggressive and often malicious deeds. The core of violent behaviour hides the aggressive organic-psychic structure, completely overwhelmed by these hostile elements, which he tries only to conceal and justify with these myths. A violent partner, who is steeped in aggression, unconsciously keeps trying to get rid of these cruel affects full of fears and terror. Therefore, he repeatedly terrorizes his closest, and sometimes also more distant people by externalizing these hostile contents to others.

Here, as an outstandingly irrational idea, we need to mention the Bible. ${ }^{38}$ It is clear that biblical texts, especially in the Old Testament, which recommend punishing children as a child-rearing method, and the husband as the absolute head of the family, are to be understood in a purely cultural and social context reflecting that period of time. Such beliefs are on several occasions harshly criticized by Christ, who pointed to a completely different commandment, the commandment of love, which should be the guideline of all life, not only on a social level. However, the violent partner, and especially the father, sometimes refers to these biblical texts, completely overlooking the fact that Christ's teaching of love for one's neighbour, in particular one's own family, wife and children, presupposes, first of all, a basic respect, love and concern for another. He elevated marriage, i.e. the relationship between husband and wife, to the highest level of God's law, since marriage is the sacrament of the love relationship between husband and wife, who are marked in their cores by the mission of mutual love and the creation of a new life. In addition, he bestowed the highest possible dignity on the human body, for he assumed the human body, thereby consecrating it. The body is therefore sacred, it is the purest sacred space, the space of the most intimate creation, and therefore must in no way fall prey to aggression.

This is, of course, followed by pure irrational denials that the violent partner is not really a bully or a criminal, as he does not use weapons. Other objects, however, are supposed to be allowed because they help in education, even though it is completely transparent that the human body, in particular children's, is not only affected by physical pain but is invaded by the most raw feelings of shame, humiliation and utter devaluation during physical abuse. The most violent

${ }^{38}$ D. G. Dutton, The Abusive Personality: Violence and Control in Intimate Relationships, New York 2007, The Guilford Press, p. 47-49; C. Policastro, M. A. Finn. Coercive control and physical violence in older adults: Analysis using data from the National Elder Mistreatment Study, "Journal of interpersonal violence" 32 (2017), pp. 319-321. 
elements of aggression flood the whole organism, in particular the most subtle brain parts, such as the amygdala, a sensory centre that collects sensations from the whole body. At the same time defence mechanisms are being built, e.g. dissociation, freezing, which is deceptive; in this frozen state, the violent, hostile affects of anger, fear, shame and sadness are preserved, and can be awakened any time, violently marking the life of the individual. Any corporal punishment can therefore scar the child for life. It is utterly paradoxical that the physical abuse of the spouse is considered a criminal act, while the same physical abuse of the child is justified by the educational methods used by the parents.

Furthermore, the violent partner uses as an excuse the myth that he was under the influence of alcohol and that he, in fact, did not know what he was doing. There is no doubt that such a myth is completely incompatible with any functional thinking. Addiction is a primarily evil, which, of course, gives rise to new evil, and here double standards apply. A driver under the influence of alcohol is severely punished, while a husband who is under the influence of alcohol should not be held liable for his acts of violence. This belief is even less acceptable when it comes to children who, because of their father's or mother's addiction become the most tragic victims of their uncontrolled impulses. This irrational thinking goes much further: that this always happens in intimate partnerships and in families where the situation is insufferable, and that it is not surprising that the partner starts drinking because he can no longer live with such an impossible wife and children who are totally undisciplined. Therefore, they are responsible for his behaviour, as he is repeatedly challenged by their nagging and violent, brutal provocation he can no longer tolerate. If they improved, then everything would be different. And yet, violence is always the complete responsibility of the violent partner who is not able to regulate and control his dysregulated aggressive affects. Violence is part of a violent partner, and it is such a profound part of his psycho-organic structure that it is only a matter of time that it will erupt.

These myths or irrational beliefs are only part of the thinking of a violent partner, on the basis of which he seeks to defend his violent actions at all times and, in doing so, often completely denies that violence is entirely his problem. These aggressive outbursts only show his insecure attachment style; in other words, that in the earliest development stages he was exposed to highly dangerous, hostile, aggressive affects that have become an essential part of his extremely insecure attachment. He is, therefore, often almost completely unable to selfregulate his affects, unable to calm himself, and therefore exaggerates in his 
perception of the outside world and sees catastrophic elements or affects, as he experiences extreme arousal. Since he is incapable of regulating this arousal, he urgently needs others. He needs a wife, he needs children, who cannot control his aggressive agitation, as he does not even allow them to; only an extremely sensitive wife could succeed in doing so. Therefore, it is a prerequisite for the therapeutic process to take place that he accepts total responsibility for his state and through this basic awareness allow the therapist to help him overcome these aggressive elements or affects: otherwise, he practically cannot be helped.

\section{Conclusion}

The violent partner is in many ways a reflection of the grave neglect and abandonment in his early youth, leaving life-long scars, however, this does not justify his violent behaviour. He is usually extremely sensitive to any actual as well as illusory discarding and develops sometimes entirely paranoid ideas and irrational thoughts, which are particularly evident in intimate couple relationships. He becomes highly demanding, trying to control everything, and when he is exposed to stressful situations in which he suspects that he will be rejected again - even if it is only his fear making him think so - he quickly becomes aggressive. His thinking becomes distorted, awakening difficult feelings. He is so completely overwhelmed by such distorted thinking, sensations, organic signalling and vibrations, that he only seeks a suitable victim of his aggressive sensations and affects, which he himself can no longer regulate. Thus, we can assert with certainty that violent partners do not react only to aggressive stimuli from the environment, but they already carry violence in their psycho-organic structure, and it is only the matter of time when they will express it. An entirely new project is waiting for us: to find out the stimuli that lead the aggressive person to completely distorted thinking, entirely inappropriate forms of expressing their affects, and in particular symptoms that reflect the internal psycho-organic experience, i.e. sensations that constantly push the violent person to the edge of what is already unacceptable. 